\title{
Implementando as políticas públicas educacionais no amazonas: os planos municipais de educação no contexto da inclusão
}

\author{
Cátia de Lemos ${ }^{1}$ \\ Claudenilson Pereira Batista ${ }^{2}$ \\ Maria Almerinda de Souza Matos ${ }^{3}$
}

Resumo. Este artigo se refere a um estudo bibliográfico e documental acerca dos Planos Municipais de Educação do Amazonas. A pesquisa visou conhecer os subsídios teóricos que norteiam as políticas educacionais com um aprofundamento nos planos atuais de educação nas três esferas governamentais no que se refere a compromissos com a educação inclusiva. Na literatura de Hoofling (2001), Mészaros (2005), Libâneo (2006), entre outros, foi possível encontrar alguns aspectos consonantes/dissonantes que conferiram o aporte teórico no que é concernente à aquisição do Direito à Educação para o segmento das pessoas com deficiência, transtornos globais do desenvolvimento e altas habilidades/superdotação. Para atingir o objetivo proposto optou-se por uma pesquisa qualitativa com enfoque dialético, por considerar as políticas públicas educacionais de inclusão, quando efetivadas, um instrumento de transformação social da condição de excluídos à protagonistas das próprias histórias. Contudo, é um convite ao debate para desvendar se, na tentativa de contemplar parte das necessidades apresentadas pelo público-alvo em questão, os Planos Municipais pesquisados estão negligenciando o devido cumprimento dos princípios assegurados pela Educação Inclusiva no Estado do Amazonas.

Palavras-chave: Políticas de inclusão. Plano Nacional de Educação. Planos Municipais de Educação.

\section{Implementing public educational policies in Amazon state: municipal education plans in inclusion context}

\begin{abstract}
This article is referred to a bibliographic and documentary study on the Municipal Education Plans of Amazonas state. The research is aimed on understanding the theoretical subsidies, which guide educational policies, as well as a deepening in current educational educational policies, as well as a deepening in current educational plans comprised in the three governmental spheres regarding to commitments into inclusive education. In Hoofling (2001), Mészaros (2005), Libâneo (2006) literature, among others, it was possible to detect some consonant/dissonant aspects, which conferred the theoretical contribution concerned to the acquisition of Education Rights on the segment of people with disability, global developmental disorders and high skills/giftedness. In order to reach

\footnotetext{
${ }^{1}$ Doutoranda em Educação do Programa de Pós-Graduação em Educação, Faculdade de Educação da UFAM AM - Bolsista da FAPEAM. catia_lemos77@ hotmail.com

${ }^{2}$ Doutorando em Educação do Programa de Pós-Graduação em Educação, Faculdade de Educação da UFAM AM; batista.claudio@outlook.com

${ }^{3}$ Doutora em Educação do Programa de Pós-Graduação em Educação, Faculdade de Educação da UFAM - AM. profalmerinda@hotmail.com
} 
the proposed objective, it was opted a qualitative research on dialectical approach, considering the public educational inclusion policies, as when they are implemented, they become an instrument of social transformation, going from exclusion ones to the protagonists of their own histories. However, it is an invitation for debating, finding out if, in an attempt to contemplate some of the presented needs for the considered target public, the surveyed Municipal Plans are neglecting the due fulfillment of ensured principles on Inclusive Education in Amazonas state.

Keywords: Inclusion policies. National Education Plan. Municipal Education Plans. 


\section{REVISTAELETRÔNICADEGRADUACÄO}

\section{INTRODUÇÃO.}

Vivencia-se atualmente um cenário marcado por inúmeras crises, seja no âmbito regional, com suas contradições sócio-históricas, seja na conjuntura socioeconômica mundial. Observando os desdobramentos dessas questões, busca-se refletir sobre alguns desafios apresentados ao educador amazônico na contemporaneidade no que se refere à implementação das Políticas Públicas Educacionais de Inclusão.

Desse modo, iniciou-se o estudo, realizando uma revisão da literatura pertinente com um aporte imprescindível da Legislação Educacional Brasileira, enfatizando um aprofundamento no Plano Nacional de Educação (2014-2024), Plano Estadual de Educação (2015-2025) do estado do Amazonas e o Plano Municipal de Educação (2015-2025) no município de Manaus, no que se refere à efetiva implementação da educação especial em um contexto de inclusão no estado do Amazonas.

Em um primeiro momento, apresentamos como foi elaborada a revisão da literatura, captação de teses afinadas com a temática, coleta de artigos científicos e algumas indicações que podem ser utilizadas para a organização do estudo.

$\mathrm{Na}$ segunda parte do trabalho explicitou-se o objetivo central do estudo que foi conhecer os subsídios teóricos que norteiam as políticas educacionais com um aprofundamento nos planos atuais de educação nas três esferas governamentais no que se refere a compromissos com a Educação Inclusiva no Amazonas. Também se apresentou a discussão de alguns resultados obtidos a partir da pesquisa realizada.

Nas considerações finais para o momento, percebeu-se o quanto a temática é desafiadora, dada à diversidade e complexidades na qual se encontra criando raízes. A pesquisa certamente não desvelou todos os aspectos do estudo. Relevante para nós é suscitar o interesse pela investigação científica para que multidimensionais olhares, reflexões e debates possam emergir trazendo novos conhecimentos, que, socializados, libertam, emancipam e fortalecem pesquisadoras e pesquisadores, trabalhadoras e trabalhadores em educação, estudantes e a sociedade como um todo, preocupados com a construção de novos rumos educacionais para o Brasil. 


\section{REVISTAELETRÔNICADEGRADUACÄO}

EPÓS-GRADUAÇÄOEM EDUCAÇÄO

REJ/UFG

\section{MÉTODO}

Optou-se neste estudo em realizar uma pesquisa qualitativa (Ludke, 2013) com enfoque dialético (Sanches, 1998), pois, nestas abordagens o pesquisador tem a oportunidade de analisar a realidade dos fatos sociais com um senso crítico, possibilitando detectar contradições ou consonâncias capazes de causar mudanças significativas na vida dos seres sociais. A esse respeito, reforça Sanches (1998) quando afirma que a dialética como teoria do conhecimento é crítica, por discutir no campo da realidade não somente a produção do conhecimento humano, mas, a ação dos homens na transformação dessa dada realidade social.

$\mathrm{O}$ instrumento selecionado para a coleta de dados foi a pesquisa bibliográfica e documental, por meio da coleta de artigos científicos disponíveis em sites reconhecidos com o descritor políticas públicas (12 resultados), políticas públicas educacionais (14 resultados) e educação inclusiva (28 resultados). O critério para a definição dos descritores e seleção dos artigos científicos foi apresentarem relação com a implementação de políticas públicas e o direito à educação para as pessoas com deficiência, transtornos globais do desenvolvimento e altas habilidades/superdotação. Utilizou-se o aporte teórico da Literatura de Hofling (2001), Mészarós (2005), Libâneo (2006), entre outros, em formato impresso/digital, e documentos legislativos oficiais como o Plano Nacional de Educação (2014/2024), o Plano Estadual de Educação (2015/2025) do Amazonas, o Plano Municipal de Educação (2015/2025) de Manaus, a Lei de Diretrizes e Bases da Educação Nacional (9394/96), entre outros, concernentes à temática em questão.

Nesta perspectiva, iniciou-se a revisão de literatura, obedecendo a 2 critérios: em um arquivo ou caderno, foram destacadas citações e pensamentos dos autores com as devidas referências, que poderiam ou não compor o estudo proposto e em outro arquivo, anotou-se palavras ou frases que podem iniciar parágrafos. Este procedimento amplia o acervo linguístico e facilita a escrita posterior, pois, a coleta de informações permanece arquivada.

Para compreender o cenário que estão inseridas as políticas públicas educacionais, tornou-se necessário analisar cada trabalho em suas peculiaridades. 


\section{REVISTAELETRÔNICADEGRADUACÄO}

EPÓS-GRADUAÇÄO EM EDUCAÇÄO

Ler com rigorosidade científica a produção coletada auxilia o pesquisador a esclarecer melhor as dúvidas acerca do objeto estudado. Dessa feita, definimos com maior clareza os autores que fizeram parte do escopo da investigação.

Lendo as teses encontradas, foi possível coletar informações como: autoria, ano e local da defesa, principais autores utilizados e procedimentos metodológicos.

As teses e dissertações foram coletadas a partir dos seguintes descritores: políticas públicas (19 teses); políticas educacionais (4 teses); políticas de inclusão (6 teses e 3 dissertações).

Alguns dos autores de base conferiram ciência às discussões apresentadas pelo estudo em questão, podendo ser retirados, mantidos ou acrescidos por outros para enriquecer a fundamentação teórica.

Com esta compreensão, não há um único modo de se realizar o estudo, já que as pessoas são diferentes, diversas também serão as formas a serem desvendadas, mas, o mais importante é ser humilde para aprender com as obras já produzidas, pois, a maturação na construção de qualquer pesquisa, elucida dúvidas, apontando novos caminhos a serem percorridos. Acredita-se que este exercício, por vezes, dolorido, mas, satisfatório, favoreceu todo o processo educativo e formativo dos pesquisadores.

\section{RESULTADOS E DISCUSSÃO}

Atualmente, presencia-se um contexto marcado por passos e descompassos de todas as ordens. Neste vendaval de acontecimentos, a educação surge no cenário da escola com um papel social definido, podendo atuar como um contraponto desafiador que interpela educadores e educandos.

Como a escola amazonense pode, a despeito do quadro de corrupção que o Brasil vivencia, educar por meio da prática pedagógica educadores e educandos críticos e cidadãos éticos respeitados em todos os direitos? Será possível implementar as ações dos planos de educação vigentes de uma maneira democrática para a escola amazônica com o atual modelo econômico que está posto?

Questões estas aguçam o pensamento, instigam e impulsionam na busca inquietante por respostas concretas que possam dar vazão aos apelos populares de resistência, 
respeito às diferenças e justiça social sustentados por inúmeros educadores amazonenses, pois, como afirma Bobbio (apud MAZZOTTA, 1996): “A atitude do bom democrático é não se iludir com o melhor e não se resignar com o pior".

Aproximando as políticas públicas de inclusão da realidade amazônica, o Plano Estadual de Educação (2015/2025) no Amazonas vem assegurando na Estratégia 4.11 que para atingir a Meta $4 *$ (Essa meta se refere à universalização do ensino para os educandos com deficiência, transtornos globais do desenvolvimento e altas habilidades/superdotação de 04 a 17 anos.) do Plano Nacional de Educação (2014/2024) é primordial:

\begin{abstract}
Fortalecer o acompanhamento e o monitoramento do acesso à escola e ao atendimento educacional especializado, bem como da permanência e do desenvolvimento escolar dos (as) alunos (as) com deficiência, transtornos globais do desenvolvimento e altas habilidades ou superdotação beneficiários (as) de programas de transferência de renda, juntamente com o combate às situações de discriminação, preconceito e violência, com vistas ao estabelecimento de condições adequadas para o sucesso educacional, em colaboração com as famílias e com os órgãos públicos de assistência social, saúde e proteção à infância, à adolescência e à juventude $[\ldots]$.
\end{abstract}

Esta estratégia impulsiona a refletir para não incorrer no erro de continuar globalizando também os preconceitos, as injustiças e o descaso generalizado com aqueles que mais necessitam, conforme relembra o pensamento de Torres (2008).

No município de Manaus-AM, de acordo com os dados coletados no Plano Municipal de Educação (2015/2025, p. 67), “[...] o município de Manaus possui 82,1\% da população de 4 a 17 anos com deficiência que frequenta a escola, logo necessita incluir os $17,9 \%$ restantes que não estão recebendo o Atendimento Educacional Especializado AEE".

Embora concordando que a implementação do atual Plano Municipal de Educação se encerra em 2025, consideramos essencial salientar que todas as crianças, incluindo as com deficiência, têm o direito à educação, de acordo com a Constituição Federal (1988), Lei de Diretrizes e Bases da Educação Nacional (9.394/96), A lei Brasileira de Inclusão (2015), entre outras.

Conforme o (Art. $7^{\circ}$.) da Lei (12.764/12) recusar a matrícula de qualquer criança, por motivo de deficiência, criminaliza o gestor escolar ou autoridade competente com multa de (3 a 20 salários mínimos) e até a perda do cargo, em caso de reincidência. 
Em relação ao Atendimento Educacional Especializado, a dupla matrícula dos

educandos em salas de recursos multifuncionais e a promoção de acessibilidade arquitetônica, de materiais, comunicacional e atitudinal são princípios sine qua non para que se efetive a educação inclusiva, previstos desde a aprovação das Leis 10.048/00 e 10.098/00, tendo continuidade na Política Nacional da Educação Especial na perspectiva da Educação Inclusiva (2008) e nas Legislações subsequentes.

Com esse caráter, o Plano Estadual de Educação (2015/2025) afirma na estratégia 4.3 que para atingir a meta 4 do Plano Nacional de Educação (2014/2024) deve-se:

Implantar e implementar, na vigência deste PEE, Salas de Recursos Multifuncionais em 100\% dos municípios do Estado, contemplando Escolas urbanas, do campo, indígenas e de comunidades quilombolas, garantindo a formação específica aos professores para atuação no Atendimento Educacional Especializado.

Com a análise dessa estratégia, percebe-se que a educação do Amazonas apresenta um grande desafio não apenas na oferta de formação, informação e transformação da concepção dos professores a respeito da inclusão educacional, mas, no enfrentamento das dificuldades de acesso a maior parte dos municípios do Estado.

Embora seja um dos objetivos dos Planos de Educação atingirem a meta 4 do Plano Nacional de Educação, sabem-se que a realidade amazônica exige algumas adaptações sejam estruturais ou na aplicabilidade dos recursos financeiros. Outro fator a ser levado em consideração é verificar como ocorrerá o monitoramento e a fiscalização das ações previstas nos respectivos Planos de Educação, para que sejam avaliadas e reelaboradas constantemente.

Ainda segundo o Plano Nacional de Educação (2014/2024), mesmo que os Estados e Municípios se encontrem livres para criarem os próprios Planos de Educação, é um dos compromissos que, (Art. $8^{\circ}$, item III) “[...] garantam o atendimento das necessidades específicas na educação especial, assegurado o sistema educacional inclusivo em todos os níveis, etapas e modalidades [...]".

A esse respeito, o Plano Municipal de Educação (2015/2025, p. 67) em Manaus afirma que:

[...] a rede municipal possui em sua estrutura atualmente: 01 Escola Especial, 25 Classes Especiais, 27 Salas de Recursos Comuns, 45 Salas de Recursos 


\section{REVISTAELETRÔNICADEGRADUACÄO}

EPÓS-GRADUAÇÄOEM EDUCAÇÄO

Multifuncional e 17 Salas de EJA inclusivo, atendendo 816 alunos público alvo da Educação especial na Rede de Ensino no ano de 2014.

Ao pensar nesses dados, ponderamos que as iniciativas de inclusão das crianças, adolescentes, jovens e adultos com deficiência, transtornos globais do desenvolvimento e altas habilidades/superdotação nos ambientes educacionais são louváveis, mas, é preciso ter a clareza de que há muitas pessoas excluídas de todo e quaisquer processo de emancipação social, precisando serem resgatadas e trazidas de volta à vida, como recorda o pensar de Lemos (2008).

No que se refere ao fato de ainda existir uma escola pública municipal com atendimento exclusivo para educandos com deficiência, transtornos globais do desenvolvimento e altas habilidades/superdotação em Manaus, é necessário salientar que existem crianças que precisam de um apoio específico para compreenderem a rotina que encontrarão no ensino comum e, conforme informações da própria Secretaria Municipal de Educação, a tendência é que esta escola, em breve, se torne um espaço de atendimento pedagógico às demais escolas da rede pública de ensino em Manaus, a exemplo de outras pelo país.

Com este caráter, o Plano Municipal de Educação (2015/2025) do município de Anamã-AM, suscitou na estratégia 4.5:

\footnotetext{
Estimular a criação de centros multidisciplinares de apoio, pesquisa e assessoria, articulados com instituições acadêmicas e integrados por profissionais das áreas de saúde, assistência social, pedagogia e psicologia, para apoiar o trabalho dos (as) professores da educação básica com os (as) alunos (as) com deficiência, transtornos globais do desenvolvimento e altas habilidades ou superdotação;
}

Observando esta estratégia, enfatiza-se a relevância do acompanhamento da equipe multidisciplinar, para os educandos, professores e familiares, pois, muitas vezes necessitam ser orientados por outros profissionais a fim de melhor poderem contribuir para o crescimento social e integral dos estudantes.

De acordo com o Plano Municipal de Educação (2015/2025) de Pauini-AM, a estratégia 4.5 visa:“Assegurar, em 5 anos de vigência deste PME, em parceria com a União e o Estado, produção de livros acessíveis, para 100\% dos alunos com deficiência visual matriculados na educação básica da rede pública de ensino do município de Pauini”. 


\section{REVISTAELETRÔNICADEGRADUACÄO}

EPÓS-GRADUAÇÄO EM EDUCAÇÄO

REJ/UFG

ITHeparius REFLECTIONIS

NÚMERO ESPECIAL

Em consonância com o Plano Nacional de Educação (2014/2024), o município de

Pauini intenciona promover a acessibilidade de materiais para educandos cegos ou com baixa visão até 2020. Esta estratégia, se efetivada, contemplará inúmeros educandos com deficiência visual que se encontram à margem dos processos educacionais, por não terem acesso a livros e demais materiais em formato acessível.

Constata-se, por meio das pesquisas que a implementação da meta 4 do Plano Nacional de Educação (2014/2024) se torna ineficaz quando há um ínfimo investimento em educação devido ao desinteresse governamental que as pessoas adquiram conhecimento; corrupção tanto moral quanto financeira e as disparidades sociais, agravadas pelos efeitos do sistema capitalista.

Impactos esses reduzem os conceitos de inclusão e exclusão a meras invenções constituídas no jogo político de um Estado que obedece mansamente às regras de uma concepção neoliberal, reforçado pelo pensar de Shor e Freire (2003), Guareschi (2003), Sanfelice (2006) e Lopes (2009).

São observadas também algumas questões que impedem no cumprimento das leis, tais como: barreiras estruturais de acesso, permanência e sucesso dos educandos com deficiência, transtornos globais do desenvolvimento e altas habilidades/superdotação nas escolas, sejam barreiras físicas ou atitudinais, como já mencionado anteriormente, na falta de aceitação do educando com deficiência nas salas de aula, fragilidades na capacitação para o trabalho do educador e demais profissionais sobre as práticas pedagógicas que atendam e incluam todos os educando em um sistema educacional inclusivo, como pressupõe a Legislação pertinente.

Partindo dessa compreensão, a educação não é uma consequência, é um processo onde as pessoas têm oportunidades únicas de serem feitas ou de se fazerem por intermédio da realidade vivida na qual os homens se produzem, pensamento salientado pelo existencialismo de Sartre (1984, p. 6), que aponta: "O homem nada mais é senão aquilo que a si mesmo se faz" e é produzido como fruto das condições bio-sócio-ambientais e da educação que recebe, primordialmente, na família e depois na escola.

Concordando com o autor muitos educandos com deficiência, transtornos globais do desenvolvimento e altas habilidades/superdotação se esforçam para superar os próprios 


\section{REVISTAELETRÔNICADE GRADUAC̄̃O}

EPÓS-GRADUAÇÄO EM EDUCAÇÄO

limites e é sabido que vários educadores tentam fazer a diferença, com atividades, metodologias e estratégias diversificadas.

Infelizmente, esses educadores são criticados pelos próprios colegas de profissão e, muitas vezes, são impedidos pelo sistema opressor e arbitrário que insiste em fazer com que todas as pessoas continuem estagnadas, alienadas e presas em suas redes de proteção.

Com este pensamento Werneck (1996), Libâneo (2006), Torres (2008), Benetti (2014), entre outros alertam para não se deixar balizar pela política de um tamanho serve para todos (One size feets all), isto é, um sistema homogeneizador que insiste que todos os educandos aprendam do mesmo modo e ao mesmo tempo, mas é preciso, nesse processo, reconhecer e respeitar a singularidade dos sujeitos e não a rejeitar.

Contudo, falar de uma maneira diferenciada de pensar a educação e construir novas metodologias de ensino-aprendizagem, é, para cada um de nós, educadores ou não, um árduo desafio. É também um objetivo concreto, um sonho a ser realizado e uma meta a ser alcançada, pois, há muito o que fazer, como se refere (FERREIRA, 2006a apud FERREIRA 2007) quando a

[...] escola está inserida na chamada 'sociedade global', onde violentas e profundas transformações no mundo do trabalho e das relações sociais vêm causando impactos desestabilizadores a toda a humanidade e, consequentemente, exigindo novos conteúdos de formação, novas formas de organização e de gestão da educação, ressignificando o valor da formação e do trabalho dos profissionais da educação.

Concordando com o pensamento de Ferreira (2007), é imprescindível repensar novas formas de viver e conviver no mundo, apesar dos sedutores convites da lógica neoliberal. Estas novas concepções poderão ensinar novos jeitos de olhar o mundo excludente que aí se encontra.

O desenvolvimento dessas novas concepções podem constituir um mundo mais solidário, justo e com igualdade de direitos, um mundo onde todos tenham o seu lugar, onde todos possam participar das decisões políticas, construindo relações mais dignas para a humanidade.

Nesta análise, urge aprofundar uma investigação que possa contribuir para o fortalecimento de uma rede de pesquisas articuladas que coloquem à disposição de estudantes, professores, pesquisadores e interessados, dados e informações relevantes sobre os avanços, 
retrocessos e resultados do estudo sobre a implementação dos Planos de Educação nas três esferas, revelando novas demandas de pesquisas no Estado do Amazonas.

O que revela reflexão, e, ao mesmo tempo suscita preocupação é que a atual conjuntura globalizante é reproduzida no campo do conhecimento, das ciências, da técnica, da política e do domínio descarado que se processa nas mais diversas maneiras de poder e dominação de uns poucos privilegiados sobre uma grande massa excluída nas sociedades contemporâneas.

Tal preocupação não pode ser um ponto de estagnação, necessitando tornar-se o ponto de partida para que sejam solucionadas, pelo menos em parte, as problemáticas levantadas pelo estudo.

\section{CONCLUSÕES}

Temos aprendido com este estudo que mesmo que o poder público (donos dos meios de produção) se recuse a enxergar as necessidades das pessoas com deficiência, transtornos globais do desenvolvimento e altas habilidades/superdotação, estas não são invisíveis e, reunidas em movimentos sociais cada vez mais organizados, continuam lançando ao mundo o desafio de serem simplesmente diferentes.

Envolvidos neste processo emancipatório, temos aprendido que é necessária a presença das pessoas com deficiência na escola, no trabalho, na praça e na comunidade para que a sociedade compreenda e aprenda a lidar com as singularidades de cada pessoa.

Temos aprendido também que, nós, os educadores não podemos nos omitir, e, precisamos continuar lutando para que a dignidade humana se antecipe à barbárie, parafraseando Freire (1996) e Adorno (2010).

Pensamos, enfim, que educar é amar profundamente as gentes e quaisquer tipos de gentes são dignas de afeto e tolerância. Por isso, a luta pela dignidade e defesa dos direitos apenas se inicia quando entendemos que as políticas públicas devem atender a todos, principalmente àqueles que ainda não aprenderam que no mundo há lugar para todos independente da cor de pele, credo, crenças, raça ou condição física.

\section{REFERÊNCIAS}


ADORNO, Theodor Wiesengrund. Educação e Emancipação. São Paulo: Paz e Terra, 2010.

BENETTI, Cláudia Casiane. Direcionando um olhar para a subjetividade singular presente no processo de ensino-aprendizagem: Um olhar psicanalítico. Disponível no site http://www.educacaoonline.pro.br/direcionando um olhar.asp?f id artigo=371 - Acessado em $26 / 12 / 2014$.

FERREIRA, Naura Syria Carapeto (org); Anita Helena Schlesner...et al. Políticas Públicas e Gestão da Educação: Polêmicas, Fundamentos e Análises. Brasília: Líber Livro, 2007.

FREIRE, Paulo. 1921-1997 Pedagogia da Autonomia: Saberes necessários à prática educativa. São Paulo: Paz e Terra, 1996.

GUARESCHI, Pedrinho A. Sociologia crítica: Alternativas de mudança. 54. ed. Porto Alegre: EDIPUCRS, 2003.

HOFLING, E. M. Estado e Políticas (Públicas) Sociais. Cadernos Cedes, ano XXI, n.55, Nov./2001

LEMOS, Cátia de. Formação e Práxis do Professor Cego ou com Baixa Visão de Manaus. Dissertação de Mestrado em Educação apresentada ao Programa de Pós-Graduação em Educação da Faculdade de Educação da Universidade Federal do Amazonas/UFAM, Manaus, AM, 2008.

LIBÂNEO, José Carlos (2006). Diretrizes Curriculares da Pedagogia - Um Adeus à Pedagogia e aos Pedagogos? Disponível no site: http://www.ced.ufsc.br/nova/Textos/ JoseCarlosLibaneo.htm - Acessado em 5 de setembro de 2013.

LOPES, Maura Corcini. Políticas de Inclusão e Governamentabilidade: Educação e Realidade. Maio/Agosto, 2009.

LÜDKE, Menga. Pesquisa em educação: abordagens qualitativas. 2.ed. Rio de Janeiro: EPU, 2013.

MÉSZARÓS, István. Edcuação Para Além do Capital. São Paulo: BoiTempo, 2005.

MAZZOTTA, M.J.S. Educação especial no Brasil: História e Políticas Públicas. São Paulo: Cortez, 1996.

SÁNCHEZ GAMBOA, Silvio, Epistemologia da Pesquisa em Educação, Campinas, Praxis. 1998

SANFELICE, José Luis. Inclusão Educacional no Brasil: Limites e Possibilidades. In: Revista de Educação PUC-Campinas, Campinas: n. 21, p. 29-40, novembro 2006

SARTRE, Jean-Paul. O existencialismo é um humanismo. In: SARTRE. Tradução de Rita Correia Guedes et al. São Paulo: Abril Cultural, 1984. 
SHOR, Ira. FREIRE, Paulo, Tradução de Adriana Lopez; Revisão Técnica de Lólio Lourenço de Oliveira. Medo e Ousadia - O Cotidiano do Professor. 11. ed. Rio de Janeiro: Paz e Terra, 2003.

TORRES, Carlos Alberto. Entrevista concedida à revista Nova Escola em maio de 2008, p. 26-30, ano XXIII, n. ${ }^{\circ} 212$.

WERNECK, Claudia. "Um tiro no preconceito". Jornal do Brasil, concedida em 14/9/1996. Disponível no site: http://intervox.nce.ufrj.br/ elizabet/tiro.htm Acessado em agosto de 2008

\section{Referências Documentais}

BRASIL. MEC - Lei n. ${ }^{\circ}$ 9.394/96 - Lei de Diretrizes e Bases da Educação Nacional, de 20 de dezembro de 1996, Direito à Educação: Subsídios para a gestão dos sistemas educacionais - Orientações gerais e marcos legais. Brasília: MEC/Seesp, 2004.

LEI N $\mathbf{N}^{0}$ 10.048, DE 8 DE NOVEMBRO DE 2000. Dá prioridade de atendimento às pessoas que especifica, e dá outras providências. Presidência da República Casa Civil Subchefia para Assuntos Jurídicos. Disponível em: http://www.planalto.gov.br/ccivil_03/leis/L10098.htm - Acessado em 5717

LEI $\mathbf{N}^{0}$ 10.098, DE 19 DE DEZEMBRO DE 2000. Estabelece normas gerais e critérios básicos para a promoção da acessibilidade das pessoas portadoras de deficiência ou com mobilidade reduzida, e dá outras providências. Presidência da República Casa Civil Subchefia para Assuntos Jurídicos. Disponível em; http://www.planalto.gov.br/ccivil 03/leis/L10098.htm - Acessado em 5717

. LEI No 12.764, DE 27 DE DEZEMBRO DE 2012. Institui a Política Nacional de Proteção dos Direitos da Pessoa com Transtorno do Espectro Autista; e altera o $§ 3^{\circ}$ do art. 98 da Lei $\mathrm{n}^{\mathrm{o}}$ 8.112, de 11 de dezembro de 1990. Presidência da República Subchefia para Assuntos Jurídicos. Disponível em http://www.planalto.gov.br/ccivil_03/_ato20112014/2012/lei/112764.htm. Acessado em 8418

. Presidência da República Subchefia para Assuntos Jurídicos MEC LEI No 13.146, DE 6 DE JULHO DE 2015. Institui a Lei Brasileira de Inclusão da Pessoa com Deficiência (Estatuto da Pessoa com Deficiência). Presidência da República Casa Civil Subchefia para Assuntos Jurídicos: Disponível em http://www.planalto.gov.br/ccivil_03/leis/L10098.htm Acessado em 5717

- DECRETO $\mathrm{N}^{\mathrm{O}}$ 6.571, DE 17 DE SETEMBRO DE 2008. Dispõe sobre o atendimento educacional especializado, regulamenta o parágrafo único do art. 60 da Lei no 9.394, de 20 de dezembro de 1996, e acrescenta dispositivo ao Decreto no 6.253, de 13 de novembro de 2007: Diário Oficial da União, Seção 1, $\mathrm{N}^{\circ} 181$, quinta-feira, 18 de setembro de 2008 - ISSN 1677-7042: 
. Plano Nacional de Educação 2014-2024 Lei no 13.005, de 25 de junho de 2014, que aprova o Plano Nacional de Educação (PNE) e dá outras providências. Brasília : Câmara dos Deputados, Edições Câmara, 2014.Atualizada em 1/12/2014.

SEDUC-AM - Documento Base do Plano Estadual de Educação Do Amazonas Governo do Estado do Amazonas. Abril, 2015.

SEMED-ANAMÃ/AM - Plano Municipal de Educação - Institui e dispõe sobre o Plano Municipal de Educação - PME e dá outras providencias. Projeto de Lei de 8 de junho de 2015. Disponível em: http://pne.mec.gov.br/planos-de-educacao/situacao-dos-planos-deeducacao. Acessado em 01/08/18

SEMED-MANAUS/AM - Plano Municipal de Educação - Documento Base. 2015/2025 Portaria Nº 0713/2014 SEMED/GS; DOM 3465.

SEMED-PAUINI/AM - Plano Municipal de Educação - cria o Plano Municipal de Educação - PME e dá outras providencias. Projeto de Lei № 248 de 14 julho de 2015. Disponível em: http://pne.mec.gov.br/planos-de-educacao/situacao-dos-planos-de-educacao. Acessado em 01/08/18 